\title{
Cyclic Tensile Strain Induces Tenogenic Differentiation of Tendon-Derived Stem Cells in Bioreactor Culture
}

\author{
Yuan Xu, ${ }^{1,2}$ Qiang Wang, ${ }^{3}$ Yudong $\mathrm{Li}^{2}{ }^{2}$ Yibo Gan, ${ }^{2}$ Pei Li, ${ }^{2}$ Songtao $\mathrm{Li}^{2}$ \\ Yue Zhou, ${ }^{1}$ and Qiang Zhou ${ }^{2}$ \\ ${ }^{1}$ Department of Orthopedics, Xinqiao Hospital, Third Military Medical University, Chongqing 400037, China \\ ${ }^{2}$ Department of Orthopedics, Southwest Hospital, Third Military Medical University, Chongqing 400038, China \\ ${ }^{3}$ Institute of Pathology and Southwest Cancer Center, Southwest Hospital, Third Military Medical University, Chongqing 400038, China
}

Correspondence should be addressed to Yue Zhou; 1072684279@qq.com and Qiang Zhou; zq_tlh@163.com

Received 17 February 2015; Revised 24 May 2015; Accepted 9 June 2015

Academic Editor: Chunfeng Zhao

Copyright (C) 2015 Yuan Xu et al. This is an open access article distributed under the Creative Commons Attribution License, which permits unrestricted use, distribution, and reproduction in any medium, provided the original work is properly cited.

Different loading regimens of cyclic tensile strain impose different effects on cell proliferation and tenogenic differentiation of TDSCs in three-dimensional (3D) culture in vitro, which has been little reported in previous literatures. In this study we assessed the efficacy of TDSCs in a poly(L-lactide-co- $\varepsilon$-caprolactone)/collagen (P(LLA-CL)/Col) scaffold under mechanical stimulation in the custom-designed 3D tensile bioreactor, which revealed that cyclic tensile strain with different frequencies $(0.3 \mathrm{~Hz}, 0.5 \mathrm{~Hz}$, and $1.0 \mathrm{~Hz}$ ) and amplitudes $(2 \%, 4 \%$, and $8 \%)$ had no influence on TDSC viability, while it had different effects on the proliferation and the expression of type I collagen, tenascin- $\mathrm{C}$, tenomodulin, and scleraxis of TDSCs, which was most obvious at $0.5 \mathrm{~Hz}$ frequency with the same amplitude and at $4 \%$ amplitude with the same frequency. Moreover, signaling pathway from microarray analysis revealed that reduced extracellular matrix (ECM) receptor interaction signaling initiated the tendon genius switch. Cyclic tensile strain highly upregulated genes encoding regulators of NPM1 and COPS5 transcriptional activities as well as MYC related transcriptional factors, which contributed to cell proliferation and differentiation. In particular, the transcriptome analysis provided certain new insights on the molecular and signaling networks for TDSCs loaded in these conditions.

\section{Introduction}

Tendon-derived stem cells (TDSCs) are a potential source of material for the generation of tissue-engineered tendons and repair of injured tendons $[1,2]$. TDSCs can differentiate into tenocytes under a variety of stimulation conditions. In vitro, the release of platelet-rich plasma [3] as well as connective tissue growth factor and ascorbic acid [4] can promote TDSCs differentiation into tenocytes. Isodirectional nanofiber scaffolds can induce the above differentiation through integrinand myosin-mediated mechanical stress pathways [5]. In vivo, tendon tissue regeneration and functional improvement have been observed after the transplantation of TDSCs in a rat patellar tendon window defect model [6].

The function of tendons is to transmit the load between muscles and bones, so tendons withstand sustained mechanical load. Tensile strain is an important part of the environment for tendon/ligament tissues in vivo and can promote the formation of tendon/ligament extracellular matrix (ECM) [7]. TDSCs are natural cells existing in the tendons [8]. The results of recent studies showed that TDSCs were very sensitive to mechanical load [9-11]. After mice were placed on a treadmill for running exercise, the proliferation rate of their TDSCs was doubled [11]. The cyclic tensile strain $(0.5 \mathrm{~Hz})$ at an amplitude of $4 \%$ or $8 \%$ promoted the alignment of TDSCs along the loading direction and the production of BMP2 [9]. In vitro, uniaxial cyclic tensile strain ( $4 \%$ amplitude, $0.5 \mathrm{~Hz}$ ) promoted the alignment of TDSCs seeded in the microgrooves along the traction direction and induced their differentiation into tenocytes, while ( $8 \%$ amplitude, $0.5 \mathrm{~Hz}$ ) tensile strain induced nontenocyte lineage differentiation [10]. These study results suggest that different cyclic tensile strain affects the biological properties of TDSCs. However, little work has been reported on cyclic tensile strain to promote the proliferation and tenogenic differentiation of TDSCs in three-dimensional (3D) culture in vitro. 
Bioreactor can be used to simulate the $3 \mathrm{D}$ growing environment and natural mechanical load in vitro to promote the regeneration of functional tendon tissues [12]. A bioreactor capable of generating cyclic tensile strain at different frequencies and amplitudes has been designed and fabricated in our previous study [13-15]. Furthermore, a 3D electrospun poly(L-lactide-co- $\varepsilon$-caprolactone)/collagen (P(LLA$\mathrm{CL}) /$ collagen) nanoyarn network satisfies the requirements for functional tendon tissue engineering which has been designed and fabricated in our previous study [16]. Additionally, in our previous study, we suggested that TDSCs displayed good proliferation and positive expressed tendonrelated extracellular matrix (ECM) genes and proteins under cyclic tensile strain ( $4 \%$ amplitude, $0.5 \mathrm{~Hz}$ ) in bioreactor culture [17]. However, the optimal mode (amplitude and frequency) of cyclic tensile strain to promote the proliferation and tenogenic differentiation of TDSCs and its underlying mechanism have not been clearly investigated.

In the present study, TDSCs were isolated from rat Achilles tendons and seeded on P(LLA-CL)/collagen scaffolds for $3 \mathrm{D}$ culture in the bioreactor. Our study evaluated the effect of cyclic tensile strain on the viability, proliferation, and tenogenic differentiation of rat TDSCs and revealed the most suitable cyclic tensile strain loading for tenogenic differentiation. Furthermore, the transcriptome microarray analysis was executed between cyclic tensile strain loaded TDSCs and cyclic tensile strain nonloaded TDSCs to elucidate the potential mechanism for tenogenic differentiation.

\section{Materials and Methods}

2.1. Mechanical Device. The mechanical device was employed for imposing cyclic tensile strain on the TDSCs-scaffold constructs. The modular bioreactor system consisted of a linear motor driver, medium circulating system, culture chamber, instrument control system, and other integrated auxiliary devices. All parameters were set according to our previous report [15]. The parameters (amplitude and frequency) of the instrument control system were adjusted to impose cyclic tensile strain on the TDSCs-scaffold constructs in the culture chamber through the linearly controlled motor driver. The stretching magnitudes (e.g., 2\%) represent the axial elongation of the constructs in length.

2.2. Cell Culture and Preparation. Cell isolation was performed according to the procedures previously described [1, 6]. Ten male Sprague-Dawley rats (4-6 weeks old, 250-300 g, Animal Center of Daping Hospital of the Third Military Medical University) were used for all experiments. Animal experiments were approved by the Institutional Animal Care and Use Committee (IACUC) of the Third Military Medical University. All rats were sacrificed. Thereafter, their bilateral tendon calcaneus were resected, weighed, and then cut into small pieces after the tendon sheaths and the middle tendon in the paratendon were removed. $100 \mathrm{mg}$ tissues were digested at $37^{\circ} \mathrm{C}$ for $1 \mathrm{~h}$ with $1 \mathrm{~mL}$ phosphate buffered saline (PBS) containing $3 \mathrm{mg}$ type I collagenase (Sigma) and $4 \mathrm{mg}$ neutral protease (Roche). The suspension was centrifuged at $500 \mathrm{~g}$ for $15 \mathrm{~min}$. The supernatant was discarded, and the remaining cells were resuspended in Dulbecco's Modified Eagle's Medium (DMEM)/F12 (1:1) (HyClone) medium containing 20\% fetal bovine serum (FBS; Invitrogen) and $1 \%$ penicillin and streptomycin (HyClone). The isolated cells were plated at an optimal cell density (about 500 cells $/ \mathrm{cm}^{2}$ ) and cultured at $37^{\circ} \mathrm{C}$ and $5 \% \mathrm{CO}_{2}$. After 810 days in culture, individual cell colonies were formed on the culture surface of the plate and were detached by local application of trypsin under microscopic visualization. The detached cell colonies were collected using a micropipette and mixed together as TDSCs passage 0 . The cells were digested with $0.25 \%$ trypsin and passaged after reaching $90 \%$ fusion. TDSCs at passage 3 preserved good colongenicity and excellent multilineage differentiation potential, as shown by Figures 1 and 2 in Supplementary Material available online at http://dx.doi.org/10.1155/2015/790804.

2.3. Scaffold Preparation and Cell Seeding. P(LLA-CL)/ collagen nanoyarn scaffolds were fabricated by electrospinning as described in our previous study [16]. A 3-0 nylon thread was presewn on the $\mathrm{P}(\mathrm{LLA}-\mathrm{CL}) /$ collagen scaffolds (length $\times$ width: $30 \mathrm{~mm} \times 25 \mathrm{~mm}$ ) along the broadside. The scaffold samples were placed into tissue-culture polystyrene plates (Costar) with a diameter of $10 \mathrm{~cm}$ and sterilized with $70 \%$ ethanol for $30 \mathrm{~min}$. The scaffold samples were then rinsed five times with PBS and immersed in DMEM/F12 medium overnight. The TDSCs (passage 3 ) were seeded on the scaffolds $\left(1 \times 10^{5}\right.$ cells/scaffold $)$. After planting TDSCs onto the scaffolds, the cell-seeded scaffolds were placed in a $37^{\circ} \mathrm{C}, 5 \% \mathrm{CO}_{2}$ incubator for $4 \mathrm{~h}$ static culture to promote cell adhesion. Then, $15 \mathrm{~mL}$ culture medium was added into the wells.

After the cell-seeded scaffolds were subjected to static culture for $24 \mathrm{~h}$, they were curled into concentric 3D constructs along their $3 \mathrm{~cm}$ long axes and then fixed on the two opposing tissue fixing columns of the culture chamber by the nylon threads under sterile conditions [17]. There were totally 3 cellscaffold constructs/culture chambers. About $80 \mathrm{~mL}$ culture medium was added into each culture chamber. The cellscaffold constructs were randomly divided into experimental and control groups. Cyclic tensile strain with different parameters (amplitude and frequency) was used in the experimental groups, and the duration of cyclic tensile strain was $3 \mathrm{~h} /$ day, as previously reported [15]; the cell-scaffold constructs in the control group were subjected to static culture without tensile strain stimulation. The samples were cultured for 7 days, and the medium was replaced twice a week.

2.4. Cell Viability and Morphology. The viability and morphology of TDSCs on the scaffold samples were evaluated using Live/Dead assays (Invitrogen) in accordance with the manufacturer's instructions [18]. The samples were imaged by laser scanning confocal microscopy (LSCM; Carl Zeiss, LSM 510 META, Germany) using the excitation wavelengths of $488 \mathrm{~nm}$ and $594 \mathrm{~nm}$. The number of viable cells and the total number of cells were counted from the images by image J software (Image J 1.46 r; National Institutes of Health), and their ratio was calculated $(n=3)$. 
TABLE 1: Real-time PCR primers used in this study. Primers for type I collagen, tenascin- $\mathrm{C}$, tenomodulin, and scleraxis and GAPDH were designed and synthesized by Sangon Biotech Co., Ltd.

\begin{tabular}{lll}
\hline Gene & Sequence & \\
\hline \multirow{2}{*}{ Type I collagen } & Forward & $5^{\prime}$ tcagaacatcacctaccactgc $3^{\prime}$ \\
& Reverse & $5^{\prime}$ attgtctttcccattcatttg $3^{\prime}$ \\
\hline \multirow{2}{*}{ Tenascin-C } & Forward & $5^{\prime}$ atcaccaccaagttcacaacag $3^{\prime}$ \\
& Reverse & $5^{\prime}$ ccatccacagattcatagagca $3^{\prime}$ \\
\hline \multirow{2}{*}{ Tenomodulin } & Forward & $5^{\prime}$ tccacaattcggcataatc $3^{\prime}$ \\
& Reverse & $5^{\prime}$ caggtccgggattctgtgt $3^{\prime}$ \\
\hline \multirow{2}{*}{ Scleraxis } & Forward & $5^{\prime}$ ccacaccaagcattttcaga $3^{\prime}$ \\
& Reverse & $5^{\prime}$ acacaaaggacggcatcac $3^{\prime}$ \\
\hline \multirow{2}{*}{ GAPDH } & Forward & $5^{\prime}$ atggtgaaggtcggagtgaa $3^{\prime}$ \\
& Reverse & $5^{\prime}$ tgggtggaatcatactggaac $3^{\prime}$ \\
\hline
\end{tabular}

2.5. Cell Proliferation. The cell proliferation of TDSCs on the scaffold samples was determined using the 4-[3-(4iodophenyl)-2-(4-nitrophenyl)-2H-5-tetrazolio]-1,3-benzene disulfonate (WST-1) assay (Roche, Germany) on day 1, day 3, day 5, and day 7; the samples were taken out from the culture chamber under sterile conditions, cut into pieces, and completely digested with $0.25 \%$ trypsin at $37^{\circ} \mathrm{C}$. After centrifugation at $1500 \mathrm{rpm}$ for $5 \mathrm{~min}$ [19], the supernatant was discarded and the resultant sediment was resuspended with $2 \mathrm{~mL}$ culture medium. According to the manufacturer's instructions, $100 \mu \mathrm{L}$ cell suspension was added into a well of the 96-well plate (10 wells/sample), and then $10 \mu \mathrm{L}$ WST-1 solution was added into each well for $3 \mathrm{~h}$ of incubation. The absorbance was measured at $450 \mathrm{~nm}$ using a microplate reader (Model 550; Bio-Rad, USA).

2.6. Quantitative Polymerase Chain Reaction (QPCR) Analysis. QPCR was employed to evaluate the mRNA expression levels of tendon-specific markers (type I collagen, tenascin$\mathrm{C}$, tenomodulin, and scleraxis) of TDSCs on the scaffold samples on day 7. The TDSCs collected from the control groups served as controls. GAPDH was used as housekeeping gene. The constructs were completely digested with $0.25 \%$ trypsin at $37^{\circ} \mathrm{C}$. After centrifugation, the cells were collected. Total RNA was extracted from these collected cells using TRIzol Reagent (Invitrogen), and then RNA concentration was determined using a UV/Vis spectrophotometer (Thermo Fisher Scientific). cDNA was transcribed reversely using an iScript cDNA synthesis kit after DNA-erase reaction (BioRad). Real-time PCR was performed with a Power SYBR Green PCR Master Mix (Applied Biosystems) on a light cycle apparatus (Applied Biosystems 7500). All primer sequences (Table 1) were designed and synthesized by Sangon Biotech Co., Ltd. (Shanghai, China). The study was repeated at least three times, and each target gene underwent three PCR cycle tests. The expression levels of target genes were calculated with $2^{-\Delta \Delta \mathrm{Ct}}$ after GAPDH standardization.

2.7. Transcriptome Microarray Analysis. Total RNA was extracted with Qiagen RNeasy Mini Kit (Qiagen). Roche Nimblegen Rat Gene Expression array analysis was performed with Affymetrix GeneChip Rat Gene 1.0 ST Array system (Affymetrix, Santa Clara, CA). Data analysis was performed using Molecular Annotation System 3.0 (http://bioinfo.capitalbio.com/mas3/).

2.8. Statistical Analysis. All of the quantitative data were presented as the mean \pm standard deviation. SPSS16.0 software was used for statistical analysis. Single-way analysis of variance (ANOVA) was used to assess the statistical significance of results between experimental group and control group, while two-way ANOVA was adopted to analyze the effects of different frequencies and amplitudes on the cell proliferation and the expression levels of specific genes. Differences were considered significant when $P<0.05$.

\section{Results}

3.1. Cyclic Tensile Strain for Cell Viability and Proliferation. The viability and morphology of TDSCs in the control group and experimental groups cultured in the culture chamber for 7 days were shown in Figure 1. It was observed that TDSCs could maintain good viability in both the control group and experimental groups. The cells presented a long spindle shape along the scaffold fiber direction in the control group (Figure 1(a)), and TDSCs in the experimental groups also exhibited a spindle-shaped morphology along with substrate fibers and the mechanical traction direction (Figures 1(a)$1(j))$. There were no significant differences in the proportion of the number of viable cells in the total number of cells between experimental groups and control group (Figure 1(k), $P>0.05, n=3)$.

The cell proliferation was measured with WST-1 assay and the results showed that (Figure 2), on day 1, there was no significant difference in cell proliferation among groups (Figure 2(a)); on day 3 , significant difference in cell proliferation was found only between the $0.5 \mathrm{~Hz} / 4 \%$ experimental group and the control group $(P<0.05$, Figure 2(b)). However, there were significant differences in cell proliferation between experimental groups and control group on day 5 and day 7 $(P<0.05$, Figures $2(\mathrm{c})$ and $2(\mathrm{~d}))$, and a significant effect was observed for both strain frequencies and amplitudes on cell proliferation, and the most obvious effect was observed in $0.5 \mathrm{~Hz}$ experimental group at the same amplitude and in $4 \%$ experimental group at the same frequency, respectively.

3.2. Gene Expression of TDSCs under Cyclic Tensile Strain. To further confirm the tendon differentiation of strain-stimulated TDSCs, we examined the tenogenic differentiation-related genes (type I collagen, tenascin$\mathrm{C}$, tenomodulin, and scleraxis) expression levels in all experimental groups after being stimulated by cyclic tensile strain and the control group (Figure 3). Compared with the control group, the significantly higher expression levels of type I collagen (Figure 3(a)) and tenascin-C (Figure 3(c)) were observed in all experimental groups except $0.3 \mathrm{~Hz} / 2 \%$ experimental group after TDSCs were stimulated by cyclic tensile strain $(P<0.05)$. In addition, we also found the significantly higher expression of tenomodulin (Figure 3(c)) and scleraxis (Figure 3(d)) in all experimental groups after 


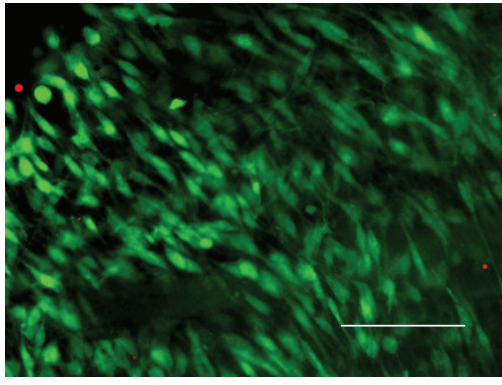

(a)

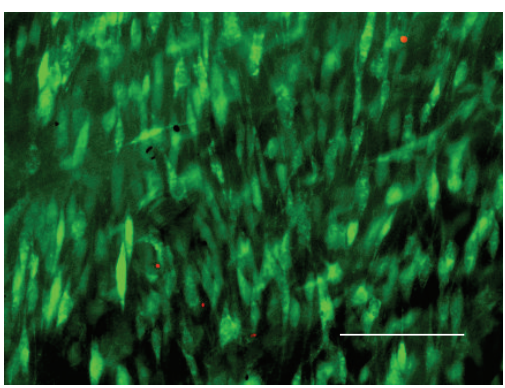

(d)

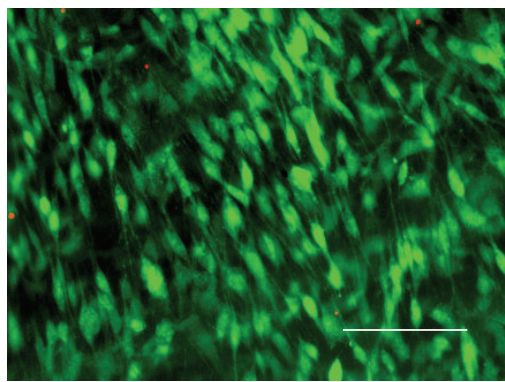

(g)

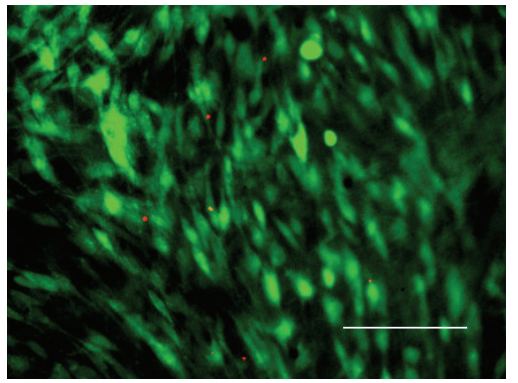

(b)

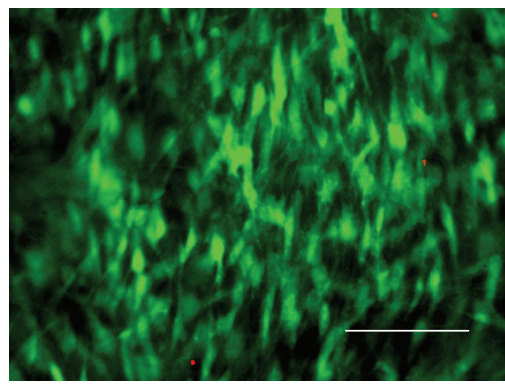

(e)

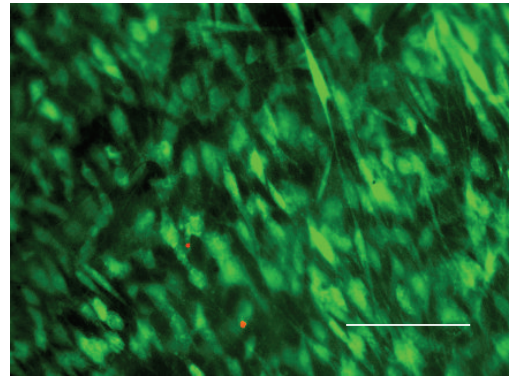

(h)

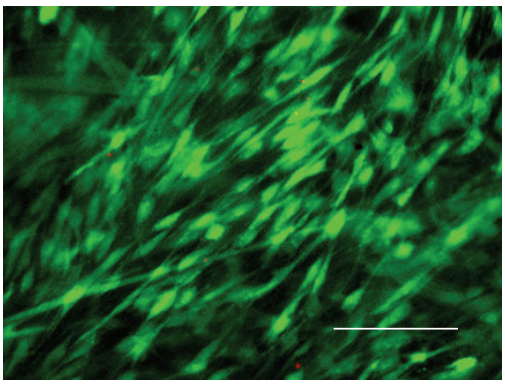

(c)

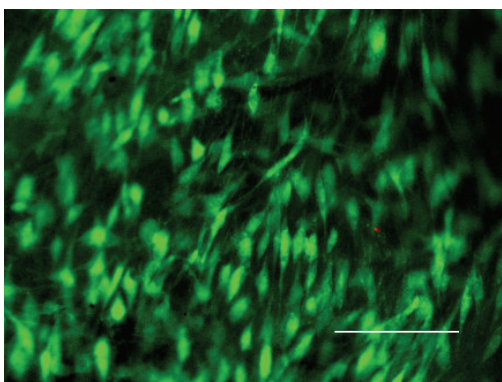

(f)

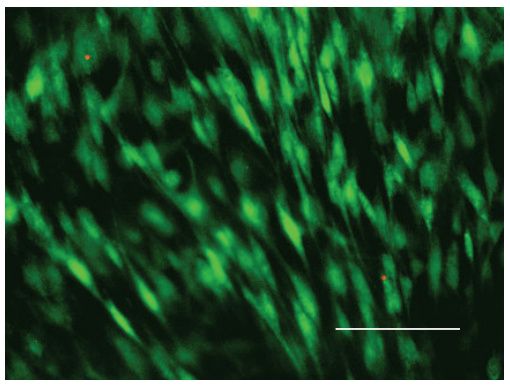

(i)

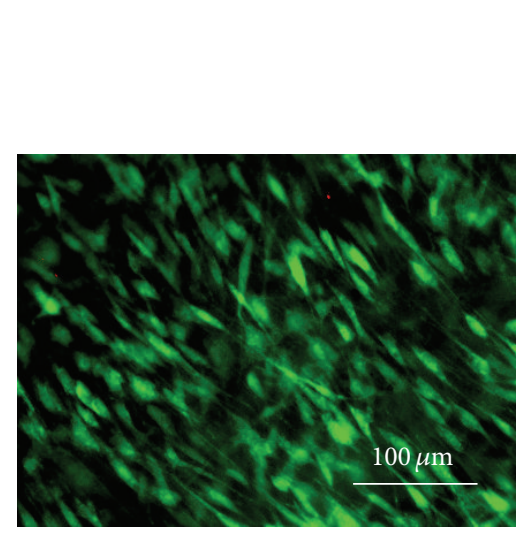

(j)

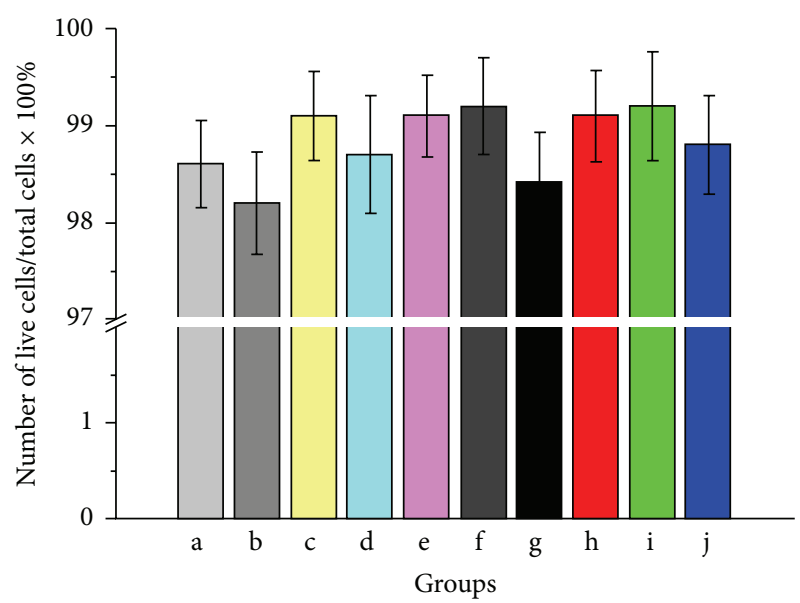

(k)

FIGURE 1: LSCM images of TDSCs on the scaffolds stained by Live/Dead assays and analysis on the proportion of the number of living cells in the total number of cells for each group. (a) Control group. (b)-(j) Experimental groups 1-9. (k) There was no statistical difference in the proportion of the number of living cells in the total number of cells between experimental groups and control group $(P>0.05, n=3)$ (in all images, scale $=100 \mu \mathrm{m})$. 


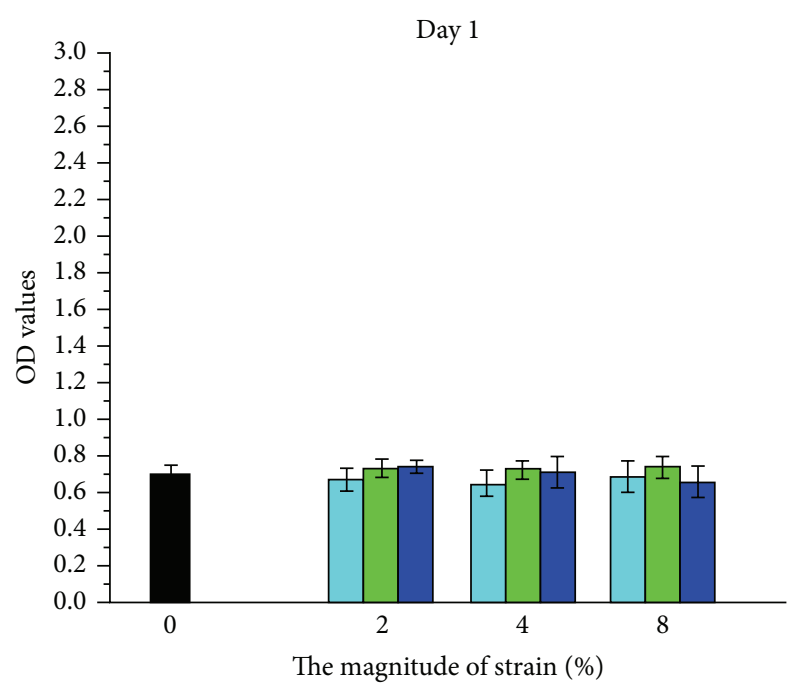

(a)

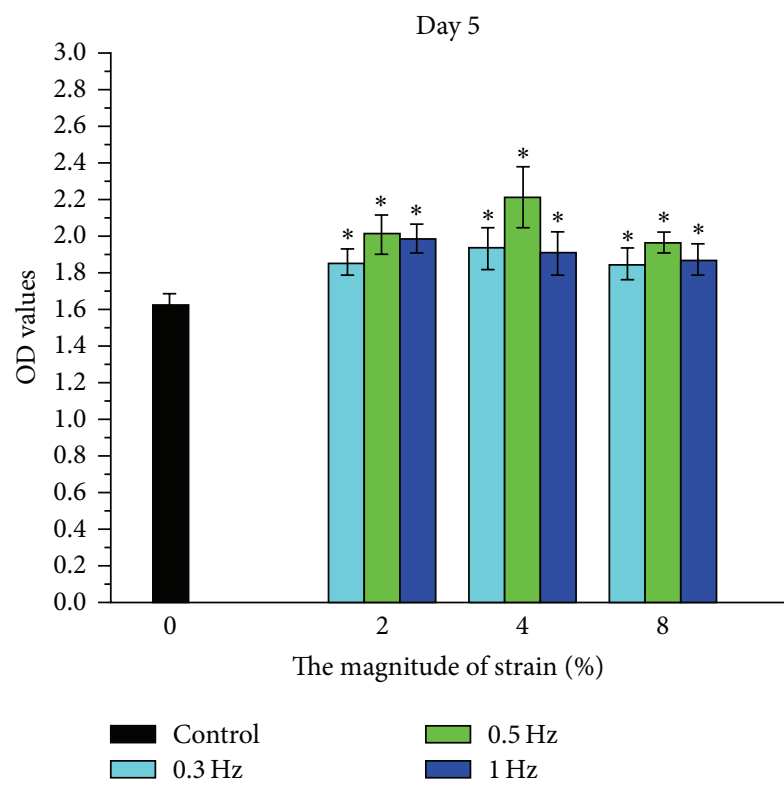

(c)

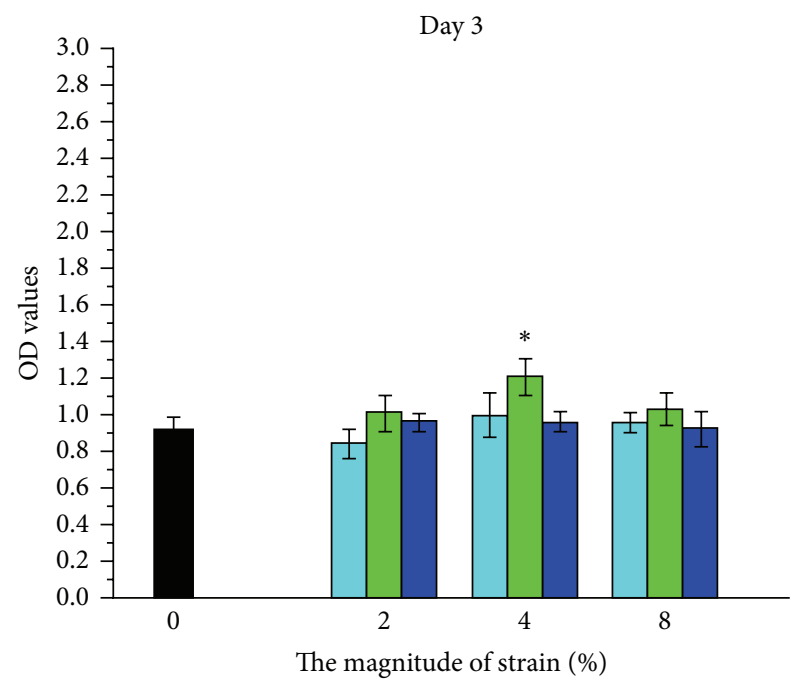

(b)

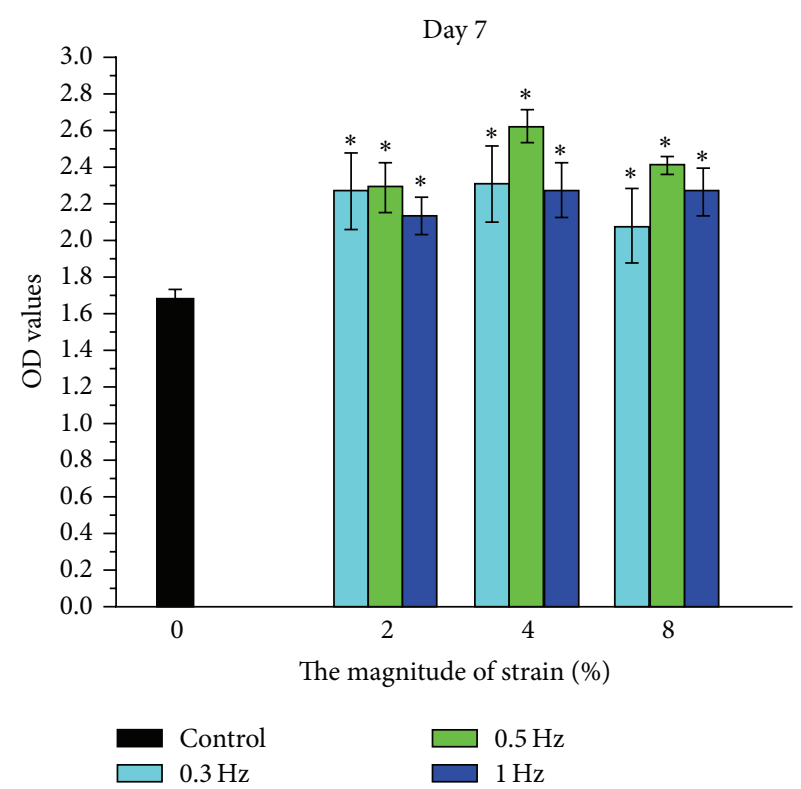

(d)

FiguRE 2: WST-1 results of TDSCs cultured in control group and different experimental groups (1 d for (a); $3 \mathrm{~d}$ for (b); $5 \mathrm{~d}$ for (c); $7 \mathrm{~d}$ for (d)). The data were expressed as mean \pm SD. The samples indicated with asterisk $(*)$ had a significant difference between experimental groups and control group $(P<0.05)(n=3)$.

TDSCs were stimulated by cyclic tensile strain, as compared with the control group. Meanwhile, a significant effect was observed for both strain frequencies and amplitudes on the expression of the four tendon-specific ECM genes of TDSCs in the cell-scaffold constructs; at the same amplitude the most obvious effect was observed in $0.5 \mathrm{~Hz}$ experimental group, while it was seen in $4 \%$ experimental group at the same frequency, respectively.

3.3. Gene Expression under Optimum Cyclic Tensile Strain for Tendon Differentiation. From the above results, distinct cell proliferation and tendon differentiation of TDSCs were regulated by cyclic tensile strain. To further explore related transduction mechanisms in cellular signaling, the transcriptome differences at the mRNA level in TDSCs with cyclic tensile strain $(0.5 \mathrm{~Hz}, 4 \%$ amplitude $)$ were analyzed with Affymetrix GeneChio Rat Gene 1.0 ST transcriptome array. TDSCs cultured on same condition without cyclic tensile strain were used as controls. Each of these arrays has 27,343 well-annotated rat targets with 722,254 distinct probes based on the November 2004 rat genome sequence (UCSC rn4, Baylor HGSC build 3.4) with comprehensive coverage of 


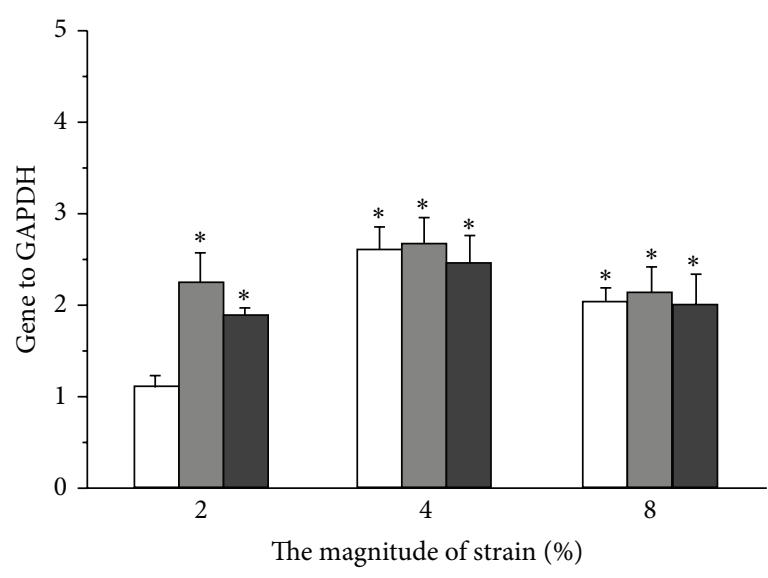

(a)

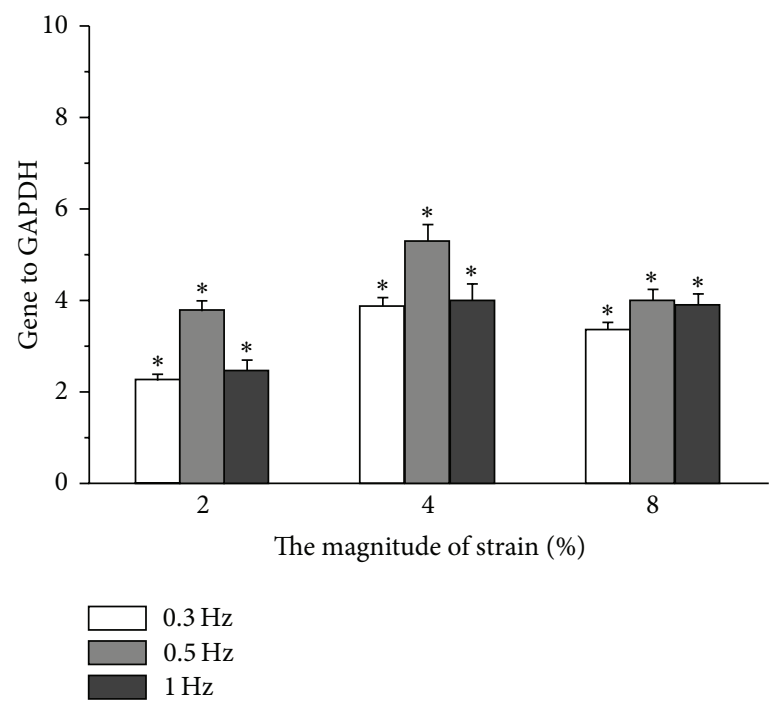

(c)

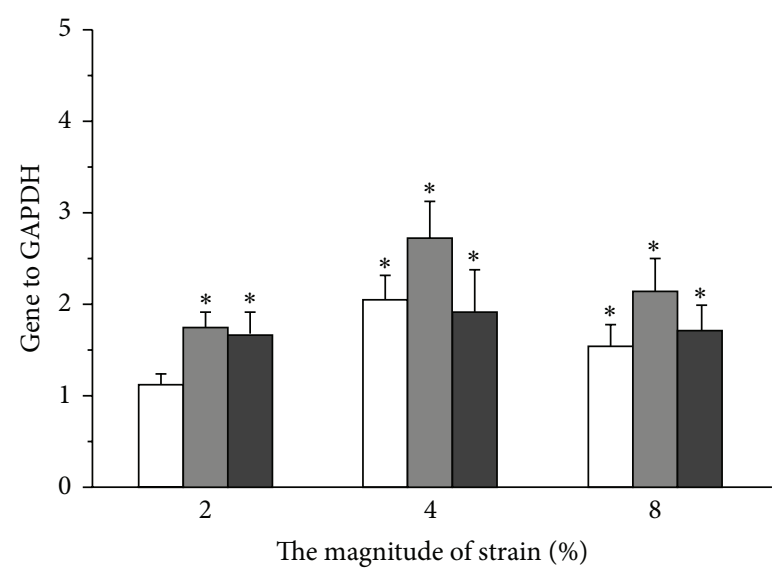

(b)

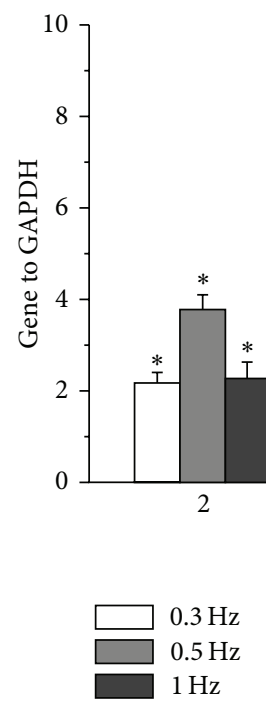

(d)

FIGURE 3: Expression of type I collagen (a), tenascin-C (b), tenomodulin (c), and scleraxis (d) of TDSCs cultured in control group and different experimental groups for 7 days. The expression levels, quantified using real-time RT-PCR, were normalized to those of housekeeping gene (GADPH). TDSCs in the control group served as controls (the expression levels of tendon ECM genes were treated as 1 in this group). The data were expressed as mean \pm SD. The samples indicated with asterisk $(*)$ had a significant difference between experimental groups and control group $(P<0.05)(n=3)$.

RefSeq, putative complete CDS GenBank transcripts. The Rat Gene 1.0 ST Array has 99.98 percent coverage of NM sequences present in the April 3, 2007, RefSeq database.

Consistent expression was found in more than $30 \%$ of the transcripts with the cyclic tensile strained mRNA samples. The transcriptional clustering profiles were significantly different from no cyclic tensile strained cells (Figure 4), which was based on a threshold of $P \leq 0.05$, and revealed that a total of $8.3 \%$ (2260 out of 27,343 transcripts) of Illumina gene sets were differentially regulated. Totally 1126 gene probe sets were upregulated and 1134 transcripts were downregulated in the cyclic tensile strained cells. Among these genes, 246 transcripts were found to be upregulated and 265 were found to be downregulated by 2 -fold or more, and 36 gene products were upregulated and 83 were downregulated by 3 -fold or more $(P \leq 0.005)$.
The top 20 upregulated and downregulated genes were shown in Table 2 . We found that the Tubulin polymerizationpromoting protein family member 3 , Tppp 3 , ranked top in the upregulated genes. Tppp3 is a specific marker for tendon sheath differentiation [20]. And IGF-1 ranked top in the downregulated genes, which was reported to drive adiposederived stem cells differentiating into chondrocyte-like cells [21]. Moreover, Gjb3, a glycogen cell marker, was expressed in the stem cell state, which was transiently increased during early stages of differentiation [22], and S100a10 calpactin I (S100 A10) was involved in regulating cell cycling and differentiation [23]. These data strongly indicated TDSCs differentiated into tendon cells under optimum cyclic tensile strain rather than other phenotypes such as chondrocyte-like cells. 
TABLE 2: The top 20 upregulated and downregulated genes with cyclic tensile strain or not.

\begin{tabular}{|c|c|c|}
\hline Fold change & Gene symbol & Gene description \\
\hline 9.32 & Tppp3 & Tubulin polymerization-promoting protein family member 3 \\
\hline 5.38 & Rrad & Ras-related associated with diabetes \\
\hline 5.31 & Aass & Aminoadipate-semialdehyde synthase \\
\hline 5.2 & Elmod1 & ELMO/CED-12 domain containing 1 \\
\hline 4.88 & Crabp2 & Cellular retinoic acid binding protein 2 \\
\hline 4.65 & S100a5 & S100 calcium binding protein A5 \\
\hline 4.44 & Gjb3 & Gap junction protein, beta 3 \\
\hline 4.2 & Kcnn4 & Potassium intermediate/small conductance calcium-activated channel, subfamily $\mathrm{N}$, member 4 \\
\hline 3.98 & Mthfs & 5,10-Methenyltetrahydrofolate synthetase (5-formyltetrahydrofolate cyclo-ligase) \\
\hline 3.97 & Lmol & LIM domain only 1 \\
\hline 3.83 & Cxcl10 & Chemokine (C-X-C motif) ligand 10 \\
\hline 3.8 & S100a10 & S100 calcium binding protein A10 \\
\hline 3.78 & Anxa8 & Annexin A8 \\
\hline 3.73 & Tspan2 & Tetraspanin 2 \\
\hline 3.68 & Ezr & Ezrin \\
\hline 3.66 & Crip1 & Cysteine-rich protein 1 (intestinal) \\
\hline 3.58 & Mlflip & Myeloid leukemia factor 1 interacting protein \\
\hline 3.54 & Clec2dll & C-type lectin domain family 2 member D-like 1 \\
\hline 3.53 & Fam111a & Family with sequence similarity 111, member A \\
\hline 3.38 & Atp2b4 & ATPase, $\mathrm{Ca}++$ transporting, plasma membrane 4 \\
\hline 0.12 & IGF-1 & Insulin-like growth factor 1 \\
\hline 0.14 & Stc1 & Stanniocalcin 1 \\
\hline 0.16 & Olr1 & Oxidized low density lipoprotein (lectin-like) receptor 1 \\
\hline 0.17 & $\mathrm{Nkd} 2$ & Naked cuticle homolog 2 (Drosophila) \\
\hline 0.18 & Lpl & Lipoprotein lipase \\
\hline 0.18 & Rgs16 & Regulator of G-protein signaling 16 \\
\hline 0.19 & LOC24906 & RoBo-1 \\
\hline 0.19 & Slc15a3 & Solute carrier family 15, member 3 \\
\hline 0.2 & Kbtbd10 & Kelch repeat and BTB (POZ) domain containing 10 \\
\hline 0.21 & Rgs2 & Regulator of G-protein signaling 2 \\
\hline 0.22 & RGD1308023 & Similar to CG5521-PA \\
\hline 0.23 & RGD1308023 & Similar to CG5521-PA \\
\hline 0.23 & RGD1308023 & Similar to CG5521-PA \\
\hline 0.24 & Bmp4 & Bone morphogenetic protein 4 \\
\hline 0.24 & Ibsp & Integrin-binding sialoprotein \\
\hline 0.24 & Kcnj2 & Potassium inwardly rectifying channel, subfamily J, member 2 \\
\hline 0.24 & Lmcdl & LIM and cysteine-rich domains 1 \\
\hline 0.25 & Agtrla & Angiotensin II receptor, type la \\
\hline 0.25 & Avprla & Arginine vasopressin receptor $1 \mathrm{~A}$ \\
\hline 0.25 & Fat4 & FAT tumor suppressor homolog 4 (Drosophila) \\
\hline
\end{tabular}

The cyclic tensile strain-regulated genes with a change $\geq 2$-fold $(P \leq 0.05)$ in either direction were subjected to gene ontology (GO) analysis for functional annotation with the KEGG pathways (Table 3). The upregulated genes were related to DNA replication and cell cycle and to the proteasome, which were consistent with the growth status differences. Interestingly, downregulated genes related to ECM-receptor interaction and focal adhesion [24]. Both expression levels of Lbsp and Lp1 were dropped to less than half of that in non-strain-stimulated cells, which suggested that cyclic tensile strain induces impaired ECM-receptor interaction. Moreover, IPA global functional analysis also showed regulated gene products mainly implicated in cell cycle control of chromosomal replication.

\subsection{Signaling Network Analysis in Cyclic Tensile Strain Induced} Tendon Differentiation. To further understand the molecular and signaling networks for TDSCs loaded in these conditions, signaling network analysis was performed with Ingenuity Knowledge Base (IKB) and Global Molecular Network 
TABLE 3: KEGG signaling pathways associated with transcriptome expression differences between the cyclic tensile strain and no treatment.

\begin{tabular}{|c|c|c|c|c|}
\hline Term & Count & $\%$ & $P$ value & Genes \\
\hline rno03030: DNA replication & 21 & 2.341137124 & $1.00 E-17$ & $\begin{array}{l}\text { LIG1, POLE, MCM2, POLA2, MCM3, LOC317415, } \\
\text { RNASEH2B, MCM4, MCM5, MCM6, RPA3, PRIM1, } \\
\text { RFC5, RPA2, MCM7, RFC4, RFC2, POLE3, POLD2, } \\
\text { PRIM2, PCNA, FEN1 }\end{array}$ \\
\hline rno04110: cell cycle & 34 & 3.790412486 & $9.83 E-16$ & $\begin{array}{l}\text { E2F1, E2F5, DBF4, TTK, CHEK1, CHEK2, CCNE2, } \\
\text { CCNE1, CDKN2A, MCM7, BUB1, MYC, CCNA2, } \\
\text { BUB3, CDC6, RBL1, ESPL1, CDC20, CDK6, MCM2, } \\
\text { CDC25C, MCM3, LOC317415, MCM4, MCM5, ATM, } \\
\text { SMC3, MCM6, CCNB1, CCND1, MAD2L1, CCNB2, } \\
\text { PLK1, PCNA, BUB1B }\end{array}$ \\
\hline rno03050: proteasome & 18 & 2.006688963 & $1.27 E-10$ & $\begin{array}{l}\text { PSMB10, PSMB4, PSMB7, PSMC6, PSMD14, PSMB6, } \\
\text { PSMC5, PSMA6, PSMC4, PSMB1, PSMA5, PSME2, } \\
\text { PSMA4, PSMB3, PSMC1, PSMA3, POMP, PSMD6 }\end{array}$ \\
\hline $\begin{array}{l}\text { rno00240: pyrimidine } \\
\text { metabolism }\end{array}$ & 20 & 2.229654404 & $1.06 E-07$ & $\begin{array}{l}\text { POLR3G, POLR1E, CTPS, POLE, POLR1A, POLR1C, } \\
\text { CAD, POLA2, POLR3D, PRIM1, TYMS, UMPS, NME2, } \\
\text { POLE3, NT5C3, RRM2, POLD2, PRIM2, UCK2, DUT }\end{array}$ \\
\hline rno03430: mismatch repair & 10 & 1.114827202 & $5.35 E-07$ & $\begin{array}{l}\text { EXO1, RFC5, RPA2, RFC4, RFC2, MSH2, LIG1, } \\
\text { POLD2, PCNA, RPA3 }\end{array}$ \\
\hline $\begin{array}{l}\text { rno04115: p53 signaling } \\
\text { pathway }\end{array}$ & 15 & 1.672240803 & $3.77 E-06$ & $\begin{array}{l}\text { BID, STEAP3, CDK6, CHEK1, CHEK2, ATM, GTSE1, } \\
\text { CCNE2, CCNB1, CCNE1, CCND1, CASP3, CDKN2A, } \\
\text { CCNB2, RRM2 }\end{array}$ \\
\hline $\begin{array}{l}\text { rno03420: nucleotide } \\
\text { excision repair }\end{array}$ & 11 & 1.226309922 & $4.08 E-05$ & $\begin{array}{l}\text { RFC5, RPA2, RFC4, POLE3, RFC2, LIG1, POLE, } \\
\text { POLD2, PCNA, ERCC1, RPA3 }\end{array}$ \\
\hline $\begin{array}{l}\text { rno00230: purine } \\
\text { metabolism }\end{array}$ & 21 & 2.341137124 & $8.38 E-05$ & $\begin{array}{l}\text { POLR3G, POLR1E, NUDT5, POLE, POLR1A, POLR1C, } \\
\text { POLA2, PPAT, GART, POLR3D, PRIM1, NME2, } \\
\text { POLE3, ATIC, NT5C3, RRM2, ADK, POLD2, PRIM2, } \\
\text { PRPS2, PRPS1 }\end{array}$ \\
\hline $\begin{array}{l}\text { rno00670: one carbon pool } \\
\text { by folate }\end{array}$ & 6 & 0.668896321 & $6.33 E-04$ & MTHFD1, MTHFS, TYMS, DHFR, ATIC, GART \\
\hline $\begin{array}{l}\text { rno03440: homologous } \\
\text { recombination }\end{array}$ & 7 & 0.780379041 & 0.001556012 & RPA2, NBN, POLD2, BRCA2, RAD54L, RPA3, RAD51 \\
\hline $\begin{array}{l}\text { rno03410: base excision } \\
\text { repair }\end{array}$ & 8 & 0.891861761 & 0.002577441 & $\begin{array}{l}\text { POLE3, NEIL3, LIG1, POLE, POLD2, PCNA, APEX1, } \\
\text { FEN1 }\end{array}$ \\
\hline rno04114: oocyte meiosis & 14 & 1.560758082 & 0.003751587 & $\begin{array}{l}\text { PPP2R1B, SGOL1, ESPL1, CDC20, CDC25C, SMC3, } \\
\text { CCNB1, CCNE2, CCNE1, MAD2L1, CCNB2, PLK1, } \\
\text { BUB1, FBXO5 }\end{array}$ \\
\hline $\begin{array}{l}\text { rno00270: cysteine and } \\
\text { methionine metabolism }\end{array}$ & 7 & 0.780379041 & 0.00748193 & GOT1, AHCY, DNMT1, AHCYL2, AMD1, APIP, SMS \\
\hline $\begin{array}{l}\text { rno05322: systemic lupus } \\
\text { erythematosus }\end{array}$ & 11 & 1.226309922 & 0.014926373 & $\begin{array}{l}\text { HIST1H2BA, HIST1H2BB, HIST1H2BH, SSB, } \\
\text { LOC682330, LOC680498, HIST1H2BM, HIST1H4B, } \\
\text { HIST2H2AC, HIST1H2AI, HIST3H2A, H2AFX, } \\
\text { HIST1H2AO }\end{array}$ \\
\hline rno03040: spliceosome & 13 & 1.449275362 & 0.018817601 & $\begin{array}{l}\text { PRPF31, PPIL1, EFTUD2, MAGOH, SNRPB2, CWC15, } \\
\text { SNRPD2, SF3B2, PRPF19, PLRG1, THOC4, LSM3, } \\
\text { SNRPF }\end{array}$ \\
\hline $\begin{array}{l}\text { rno00480: glutathione } \\
\text { metabolism }\end{array}$ & 7 & 0.780379041 & 0.039033496 & LAP3, ODC1, GSTA2, GSTA4, RRM2, SMS, GCLM \\
\hline rno03020: RNA polymerase & 5 & 0.557413601 & 0.039888482 & POLR3G, POLR1E, POLR1A, POLR1C, POLR3D \\
\hline $\begin{array}{l}\text { rno04512: ECM-receptor } \\
\text { interaction }\end{array}$ & 16 & 2.285714286 & $7.51 E-07$ & $\begin{array}{l}\text { IBSP, COL4A2, ITGA1, ITGA11, LAMA2, LAMA4, } \\
\text { LAMB2, LAMA5, ITGB8, ITGA7, TNN, AGRN, } \\
\text { LAMC1, COL11A1, THBS2, THBS4 }\end{array}$ \\
\hline rno04510: focal adhesion & 24 & 3.428571429 & $3.96 E-06$ & $\begin{array}{l}\text { IBSP, COL4A2, VAV3, ITGA11, ITGA1, IGF1, HGF, } \\
\text { MYL9, LAMA2, LAMA4, LAMB2, LAMA5, ITGB8, } \\
\text { ITGA7, PDGFRA, PDGFRB, TNN, LAMC1, EGF, } \\
\text { COL11A1, FIGF, THBS2, SHC4, THBS4 }\end{array}$ \\
\hline
\end{tabular}


TABLE 3: Continued.

\begin{tabular}{lccll}
\hline Term & Count & $\%$ & $P$ value & Genes \\
$\begin{array}{l}\text { rno05414: dilated } \\
\text { cardiomyopathy }\end{array}$ & 11 & 1.571428571 & 0.003630871 & $\begin{array}{l}\text { LAMA2, ADCY4, ITGB8, ITGA7, ADCY6, ITGA11, } \\
\text { ITGA1, IGF1, CACNB3, CACNA1C, SGCB }\end{array}$ \\
\hline $\begin{array}{l}\text { rno04270: vascular smooth } \\
\text { muscle contraction }\end{array}$ & 12 & 1.714285714 & 0.00645965 & $\begin{array}{l}\text { RAMP3, ADCY4, AGTR1A, ADORA2A, PPP1R12B, } \\
\text { ADCY6, AVPR1A, NPR2, PRKG1, CACNA1C, PRKCE, } \\
\text { MYL9 }\end{array}$ \\
\hline $\begin{array}{l}\text { rno00230: purine } \\
\text { metabolism }\end{array}$ & 14 & 2 & 0.010450898 & $\begin{array}{l}\text { ADCY4, ENPP3, ADCY6, PDE10A, PDE3A, NPR2, } \\
\text { PDE4, AMPD3, POLD4, PDE7B, PDE4B, ENTPD4, } \\
\text { ENTPD1, ENTPD2 }\end{array}$ \\
\hline $\begin{array}{l}\text { rno05410: hypertrophic } \\
\text { cardiomyopathy (HCM) }\end{array}$ & 9 & 1.285714286 & 0.02148213 & $\begin{array}{l}\text { LAMA2, ITGB8, ITGA7, ITGA11, ITGA1, IGF1, } \\
\text { CACNB3, CACNA1C, SGCB }\end{array}$ \\
$\begin{array}{l}\text { rno05412: arrhythmogenic } \\
\text { right ventricular } \\
\text { cardiomyopathy (ARVC) }\end{array}$ & 8 & 1.142857143 & 0.031599478 & $\begin{array}{l}\text { LAMA2, ITGB8, ITGA7, ITGA11, ITGA1, CACNB3, } \\
\text { CACNA1C, SGCB }\end{array}$ \\
$\begin{array}{l}\text { rno04614: } \\
\text { renin-angiotensin system }\end{array}$ & 4 & 0.571428571 & 0.046740741 & AGTR1A, MME, ANPEP, ENPEP \\
\hline
\end{tabular}

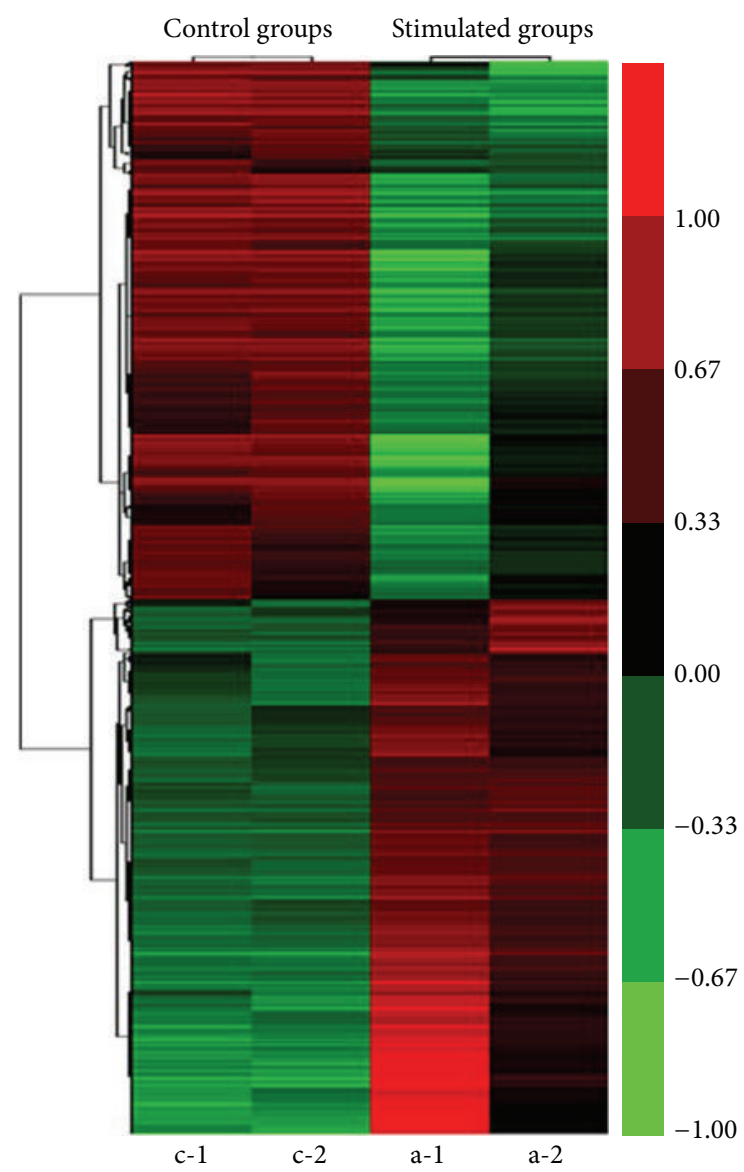

FIgURE 4: Transcriptome microarray analysis of TDSCs in the stimulated groups (a-1 and a-2) and control groups (c-1 and c-2), calculated with cluster 3.0 .

(GMN) from the Ingenuity System Database, which provided genomic interaction and signal networks information. The gene interactions and biological processes networks were analyzed by IPA program with the regulated genes with a ratio $\geq 2(P<0.05)$. IPA program gave a score for each signaling network according to the gene expression ratios, in which highest score indicated the most highly regulated network. Here, two highest scored networks with described relationships were analyzed between a series of gene subset and interacting neighboring genes in this dataset (Figures 5 and 6). Upregulated genes in the network were shown with red symbols and downregulated genes were shown with green symbols. Network 1 (Figure 5) received the highest score (44) and contains 34 significantly regulated genes. Two transcription regulators, COPS5 and NPM1, were located in the central position of this network, which connected with several important canonical pathways related to cell proliferation. NPM1 expression indicated elevated DNA replication [25]. This signaling included the significantly upregulated genes, ATM, COPS5, NPM1, RPA2, RPA3, and UBE2N, and downregulated genes, IKBKE and GRK5. The COPS5regulated transcripts were mainly upregulated (red symbols) except for MEF2C and CPNE7 (green symbols). The NPM1 and COPS5 networks are involved in cellular and molecular functions of DNA replication, recombination and repair, cellular compromise, cell death, and survival [26].

Network 2 (Figure 6) received a score of 36 which contained 32 genes. MYC, as a hub of connectivity [27], appeared to play a central role possessing 30 edges via direct connections. Among them, GRPEL, TMEM126A, GCSH, CST6, TMEM97, NOL9, GGH, FAM129A, NDNL2, Arf2, UTP15, MINA, and Clec2d were significantly elevated, whereas MGAT1, IMPA2, MTHFR, COL14A1, DDX17, mir365, and GLS2 were downregulated as shown. Five other transcripts belonging to the SMC (structural maintenance of chromosomes) and non-SMC condensin complex were also present as the downstream of MYC signaling [28]. All of them were upregulated. Altogether, Network 2 was in correlation with a set of cellular and molecular functions which include 


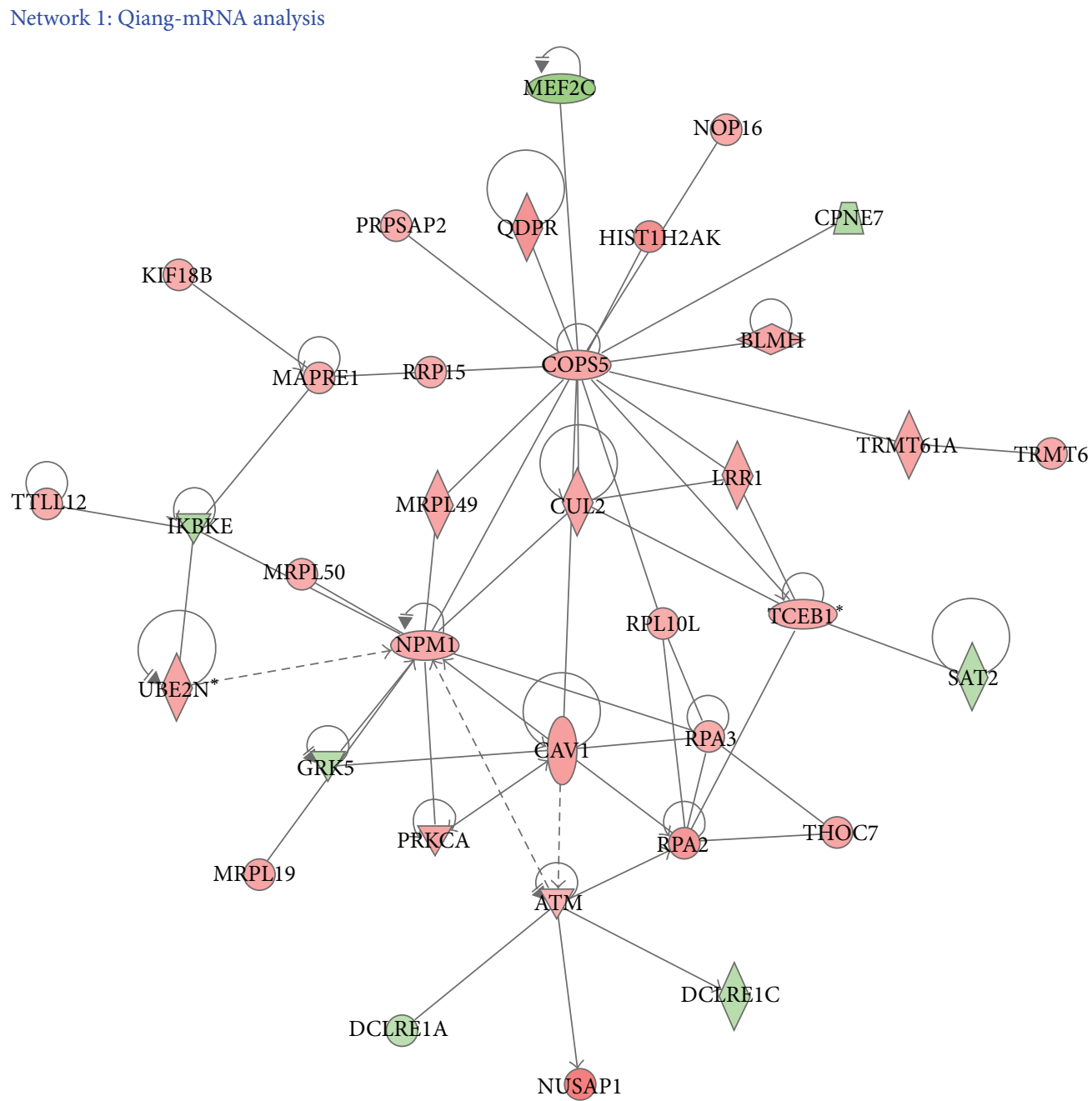

(c) 2000-2014 QIAGEN. All rights reserved.

FIGURE 5: Ingenuity interactome analysis of the effect of cyclic tensile strain-affected gene expression was performed using the Ingenuity software. The gene products in network were displayed as nodes, and the biological relationships between the nodes were displayed as lines. Different shapes represented different functional classes of gene products. The color of each node indicates the degree of upregulation (red) or downregulation (green) of the respective gene transcript. Network 1: the COPS5 and NPM1 network connected with several important canonical pathways, which shows the connection of this network to DNA replication.

DNA replication, recombination and repair, cellular assembly and organization, and gene expression.

\section{Discussion}

When subjected to mechanical stimuli, viable tissues will undergo endogenous changes in cell morphology, tissue building, and mechanical properties [29, 30]. It is reported that mechanical stimulation plays an important role in the induction of cell proliferation and differentiation, cell alignment, extracellular matrix synthesis, and tissue remodeling $[31,32]$. Physical and mechanical factors play a critical role in controlling self-renewal and lineage specification of the stem cells [33]. This study aimed at investigating the optimal mode (amplitude and frequency) of cyclic tensile strain to promote the proliferation and tenogenic differentiation of TDSCs and its underlying mechanism in $3 \mathrm{D}$ culture in vitro.

Our previous experimental study confirmed that P(LLA$\mathrm{CL}$ /collagen nanoyarn scaffolds had no effects on tenocyte adhesion and proliferation and tenocytes well spread along with aligned substrate fibers exhibiting a spindle-shaped morphology [16]. The present study also showed that TDSCs could maintain good viability on the scaffolds and grow along the scaffold fiber direction and the direction of tensile strain stimuli.

Many studies have confirmed that mechanical stimulation can promote cell proliferation, which depends on its type, magnitude, frequency, and duration. Cyclic tensile strain stimulation can promote the proliferation of anterior cruciate ligament fibroblasts, and the level of cell proliferation 
Network 2: Qiang-mRNA analysis

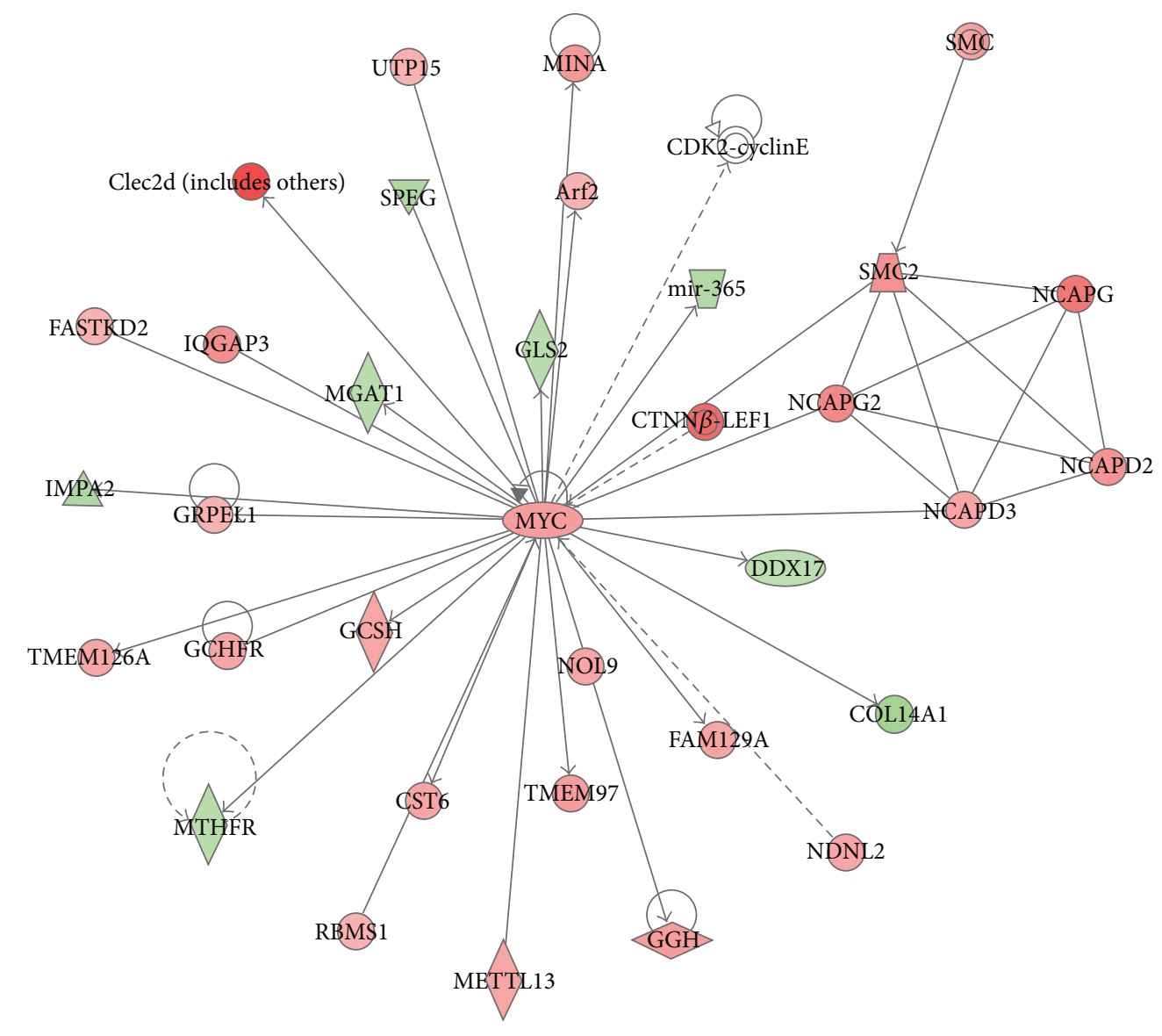

(c) 2000-2014 QIAGEN. All rights reserved.

FIGURE 6: MYC signaling. MYC as a hub of connectivity appeared to play a central role possessing 30 targeted genes via direct connections.

is higher with the increase of tensile strain amplitude (4\%8\%) [34]. Obaid and Connell [8] reported that the proliferation of tendon fibroblasts induced by mechanical stimulation depended on the range of tensile strain. Cell proliferation can reflect the activity changes of cells under different modes of mechanical stimulation. In this study, cyclic tensile strain at different frequencies and amplitudes had different effects on the proliferation of TDSCs in various experimental groups. Under cyclic tensile strain, at frequencies ranging from $0.3 \mathrm{~Hz}$ to $1.0 \mathrm{~Hz}$, the proliferation of TDSCs showed a trend of increase at first but later it showed a trend of decrease, and the most obvious stimulation effect was observed at $0.5 \mathrm{~Hz}$; an identical trend was observed at amplitudes ranging from $2 \%$ to $8 \%$, and the most obvious stimulation was found at $4 \%$. This might be because there was a certain optimal stimulation threshold and limitation within the selected frequency or amplitude range; when the frequency or amplitude approached the threshold from the minimal value, the proliferative activity of cells was enhanced, and when the frequency or amplitude exceeded the limitation from the maximum value, the proliferative activity of cells was depressed, which is similar to the results of a recent study on the effects of fluid shear strain and fluid pressure on cell proliferation [35].

The upregulation of markers indicative of a mature, differentiated cell phenotype is the most often judgment of differentiation [36]. Type I collagen is the primary matrix components of natural tendon tissues. Type I collagen is accounting for about $85 \%$ of the dry weight of tendon tissues, and it is also the most important protein constituting tendon fibers against tensile strain. Tenascin-C is used as a tendon marker in embryonic tendon [37]. Expressions of scleraxis and tenomodulin are frequently analyzed to confirm differentiation towards a tenocyte lineage. Recent studies have shown that tensile strain ( $10 \%$ amplitude, $1 \mathrm{~Hz}, 2 \mathrm{~h} /$ day) can stimulate embryonic stem cells (ESCs) to express tendonrelated genes, type I and III collagen, Epha 4, and scleraxis [38], and cyclic tensile strain can promote the tenogenic differentiation of mesenchymal stem cells (MSCs) and the repair of injury tendon $[39,40]$. Our study results showed higher expression levels of tenogenic differentiation-related mRNA when TDSCs were stimulated by cyclic tensile strain. These gene expression changes were correlated with the amplitude and frequency of cyclic tensile strain. Real-time PCR results showed that there was a significant increase 
in the expression levels of tenogenic differentiation-related mRNA when TDSCs were stimulated by cyclic tensile strain in all experiments. At the same amplitude, the stimulation effects of strain on the expression of type I collagen, tenascin$\mathrm{C}$, tenomodulin, and scleraxis showed frequency-dependent increasing and then decreasing trend at different frequencies, wherein the effect at $0.5 \mathrm{~Hz}$ was the strongest; at the same frequency, the stimulation effects of strain on the expression of type I collagen, tenascin- $\mathrm{C}$, tenomodulin, and scleraxis showed amplitude-dependent increasing and then decreasing trend at different amplitudes, wherein the effect at $4 \%$ was the strongest. The frequency and amplitude of cyclic tensile strain imposed have no superimposing or offsetting effects on the expression levels of these four genes. Microscopic tearing of tendon fibers occurs when tendons are stretched over $4 \%$ and macroscopic failure occurs when tendons are stretched beyond $8-10 \%$ strain [41]. Our results showed that, at various frequencies/amplitudes, cyclic tensile strain could induce the expression of tenogenic differentiation-related genes of TDSCs; the amplitude of $4 \%$ and the frequency of $0.5 \mathrm{~Hz}$ might be the optimal induction condition.

Results from transcriptome microarray further confirmed that cyclic tensile strain induced TDSCs had distinct cell proliferation signaling, which can explain better cell viability and proliferation with cyclic tensile strain treatment. More importantly, cell/material interface has been shown to exert considerable influence on function and differentiation of TDSC. ECM-receptor signaling played a crucial role in this process [24]. Impaired ECM-receptor interaction signaling pathway was also found when treated with cyclic tensile strain, which means cyclic tensile strain can inhibit this signal to trigger TDSC differentiation. Therefore, reduced ECM receptor interaction signaling may initiate tendon genius switch.

We showed that cyclic tensile strain highly upregulates genes encoding regulators of NPM1 and COPS5 transcriptional activities as well as MYC related transcriptional factors. The networks are mainly contributed to cellular and molecular functions of DNA replication, recombination and repair, cellular compromise, cell death and survival, cellular assembly and organization, and gene expression [25-28], which also played a crucial role for tendon differentiation and cell proliferation.

In addition, one limitation of this study is that the amplitude and frequency as well as duration ranges of cyclic tensile strain are not detailed enough, so we will perform further screening. Besides, the cyclic tensile strain we used may be different from the composite mechanical stimulation withstood by natural tendon tissues in vivo; thus we will further improve our mechanical force devices to provide multiple modes of mechanical stimulation.

\section{Conclusions}

The custom-designed 3D tensile bioreactor used in our study provides testimonies that cyclic tensile strain with different parameters has different effects on the proliferation and tenogenic differentiation of TDSCs; cyclic tensile strain with $0.5 \mathrm{~Hz}$ at $4 \%$ amplitude may be the optimal condition for the proliferation and tenogenic differentiation of TDSCs. Moreover, the transcriptome analysis provided certain new insights on the molecular and signaling networks for TDSCs loaded in these conditions.

\section{Disclosure}

Yuan Xu and Qiang Wang are co-first authors.

\section{Conflict of Interests}

The authors declare that there is no conflict of interests regarding the publication of this paper.

\section{Authors' Contribution}

Conception and design of experiments were done by Qiang Zhou and Yue Zhou. Experiments were performed by Yuan $\mathrm{Xu}$, Qiang Wang, Yudong Li, Yibo Gan, Pei Li, and Songtao Li. Data analysis was done by Yuan Xu and Qiang Wang. Yuan $\mathrm{Xu}$ and Qiang Wang wrote the paper. Yuan Xu, Qiang Wang, Yue Zhou, and Qiang Zhou contributed equally to this work.

\section{Acknowledgment}

This study was funded by the National Natural Science Foundation of China (Grant nos.: 2006AA02Z4E3 and 81027005).

\section{References}

[1] J. Zhang and J. H.-C. Wang, "Characterization of differential properties of rabbit tendon stem cells and tenocytes," $B M C$ Musculoskeletal Disorders, vol. 11, article 10, 2010.

[2] P. P. Y. Lui, "Identity of tendon stem cells-how much do we know?" Journal of Cellular and Molecular Medicine, vol. 17, no. 1, pp. 55-64, 2013.

[3] J. Zhang and J. H.-C. Wang, "Platelet-rich plasma releasate promotes differentiation of tendon stem cells into active tenocytes," The American Journal of Sports Medicine, vol. 38, no. 12, pp. 2477-2486, 2010.

[4] M. Ni, Y. F. Rui, Q. Tan et al., "Engineered scaffold-free tendon tissue produced by tendon-derived stem cells," Biomaterials, vol. 34, no. 8, pp. 2024-2037, 2013.

[5] Z. Yin, X. Chen, J. L. Chen et al., "The regulation of tendon stem cell differentiation by the alignment of nanofibers," Biomaterials, vol. 31, no. 8, pp. 2163-2175, 2010.

[6] M. Ni, P. P. Y. Lui, Y. F. Rui et al., "Tendon-derived stem cells (TDSCs) promote tendon repair in a rat patellar tendon window defect model," Journal of Orthopaedic Research, vol. 30, no. 4, pp. 613-619, 2012.

[7] D. Deng, W. Liu, F. Xu et al., "Engineering human neo-tendon tissue in vitro with human dermal fibroblasts under static mechanical strain," Biomaterials, vol. 30, no. 35, pp. 6724-6730, 2009.

[8] H. Obaid and D. Connell, "Cell therapy in tendon disorders: what is the current evidence?" American Journal of Sports Medicine, vol. 38, no. 10, pp. 2123-2132, 2010.

[9] Y. F. Rui, P. P. Y. Lui, M. Ni, L. S. Chan, Y. W. Lee, and K. M. Chan, "Mechanical loading increased BMP-2 expression which 
promoted osteogenic differentiation of tendon-derived stem cells," Journal of Orthopaedic Research, vol. 29, no. 3, pp. 390396, 2011.

[10] J. Zhang and J. H.-C. Wang, "Mechanobiological response of tendon stem cells: implications of tendon homeostasis and pathogenesis of tendinopathy," Journal of Orthopaedic Research, vol. 28, no. 5, pp. 639-643, 2010.

[11] M. Szczodry, J. Zhang, C. Lim et al., “Treadmill running exercise results in the presence of numerous myofibroblasts in mouse patellar tendons," Journal of Orthopaedic Research, vol. 27, no. 10, pp. 1373-1378, 2009.

[12] T. Wang, B. S. Gardiner, Z. Lin et al., "Bioreactor design for tendon/ligament engineering," Tissue Engineering Part B: Reviews, vol. 19, no. 2, pp. 133-146, 2013.

[13] L. Song, P. Duan, P. Guo et al., "Downregulation of miR-223 and miR-153 mediates mechanical stretch-stimulated proliferation of venous smooth muscle cells via activation of the insulinlike growth factor-1 receptor," Archives of Biochemistry and Biophysics, vol. 528, no. 2, pp. 204-211, 2012.

[14] L. Song, Q. Zhou, P. Duan et al., "Successful development of small diameter tissue-engineering vascular vessels by our novel integrally designed pulsatile perfusion-based bioreactor," PLoS ONE, vol. 7, no. 8, Article ID e42569, 2012.

[15] S.-T. Li, Y. Liu, Q. Zhou et al., "A novel axial-stress bioreactor system combined with a substance exchanger for tissue engineering of 3D constructs," Tissue Engineering, Part C: Methods, vol. 20, no. 3, pp. 205-214, 2014.

[16] Y. Xu, J. Wu, H. Wang et al., "Fabrication of electrospun poly (L-lactide-co- $\varepsilon$-caprolactone)/collagen nanoyarn network as a novel, three-dimensional, macroporous, aligned scaffold for tendon tissue engineering," Tissue Engineering Part C: Methods, vol. 19, no. 12, pp. 925-936, 2013.

[17] Y. Xu, S. Dong, Q. Zhou et al., "The effect of mechanical stimulation on the maturation of TDSCs-poly(L-lactide-coe-caprolactone)/collagen scaffold constructs for tendon tissue engineering," Biomaterials, vol. 35, no. 9, pp. 2760-2772, 2014.

[18] S. D. Subramony, B. R. Dargis, M. Castillo et al., "The guidance of stem cell differentiation by substrate alignment and mechanical stimulation," Biomaterials, vol. 34, no. 8, pp. 1942-1953, 2013.

[19] W. Shi, D. Nie, G. Jin et al., "BDNF blended chitosan scaffolds for human umbilical cord MSC transplants in traumatic brain injury therapy," Biomaterials, vol. 33, no. 11, pp. 3119-3126, 2012.

[20] J. A. Staverosky, B. A. Pryce, S. S. Watson, and R. Schweitzer, "Tubulin polymerization-promoting protein family member 3 , Tppp3, is a specific marker of the differentiating tendon sheath and synovial joints," Developmental Dynamics, vol. 238, no. 3, pp. 685-692, 2009.

[21] S. M. Richardson, J. M. Curran, R. Chen et al., "The differentiation of bone marrow mesenchymal stem cells into chondrocytelike cells on poly-l-lactic acid (PLLA) scaffolds," Biomaterials, vol. 27, no. 22, pp. 4069-4078, 2006.

[22] Y. Koch, B. van Fürden, S. Kaiser et al., "Connexin 31 (GJB3) deficiency in mouse trophoblast stem cells alters giant cell differentiation and leads to loss of oxygen sensing," Biology of Reproduction, vol. 87, no. 2, Article ID Article 37, 2012.

[23] C. W. Heizmann, "The multifunctional S100 protein family," Methods in Molecular Biology, vol. 172, pp. 69-80, 2002.

[24] N. R. Schiele, J. E. Marturano, and C. K. Kuo, "Mechanical factors in embryonic tendon development: potential cues for stem cell tenogenesis," Current Opinion in Biotechnology, vol. 24, no. 5, pp. 834-840, 2013.
[25] S. E. Polo and S. P. Jackson, "Dynamics of DNA damage response proteins at DNA breaks: a focus on protein modifications," Genes and Development, vol. 25, no. 5, pp. 409-433, 2011.

[26] H. Wang, D. Dey, I. Carrera et al., “COPS5 (Jab1) Protein increases brta Site processing of amyloid precursor protein and amyloid beta peptide generation by stabilizing ranbp 9 protein levels," The Journal of Biological Chemistry, vol. 288, no. 37, pp. 26668-26677, 2013.

[27] L. M. Quinn, J. Secombe, and G. R. Hime, "Myc in stem cell behaviour: insights from Drosophila," Advances in Experimental Medicine and Biology, vol. 786, pp. 269-285, 2013.

[28] K. Jeppsson, T. Kanno, K. Shirahige, and C. Sjögren, "The maintenance of chromosome structure: positioning and functioning of SMC complexes," Nature Reviews Molecular Cell Biology, vol. 15, no. 9, pp. 601-614, 2014.

[29] H. A. Benhardt and E. M. Cosgriff-Hernandez, "The role of mechanical loading in ligament tissue engineering," Tissue Engineering-Part B: Reviews, vol. 15, no. 4, pp. 467-475, 2009.

[30] K. Y. Xie, L. Yang, K. Chen, and Q. Li, "In vitro study of the effect of cyclic strains on the dermal fibroblast (GM3384) morphology-mapping of cell responses to strain field," Medical Engineering and Physics, vol. 34, no. 7, pp. 826-831, 2012.

[31] J. A. Hannafin, E. A. Attia, R. Henshaw, R. F. Warren, and M. M. Bhargava, "Effect of cyclic strain and plating matrix on cell proliferation and integrin expression by ligament fibroblasts," Journal of Orthopaedic Research, vol. 24, no. 2, pp. 149-158, 2006.

[32] G. Yang, R. C. Crawford, and J. H.-C. Wang, "Proliferation and collagen production of human patellar tendon fibroblasts in response to cyclic uniaxial stretching in serum-free conditions," Journal of Biomechanics, vol. 37, no. 10, pp. 1543-1550, 2004.

[33] D. Li, J. Zhou, F. Chowdhury, J. Cheng, N. Wang, and F. Wang, "Role of mechanical factors in fate decisions of stem cells," Regenerative Medicine, vol. 6, no. 2, pp. 229-240, 2011.

[34] S. A. Park, I. A. Kim, Y. J. Lee et al., "Biological responses of ligament fibroblasts and gene expression profiling on micropatterned silicone substrates subjected to mechanical stimuli," Journal of Bioscience and Bioengineering, vol. 102, no. 5, pp. 402412, 2006.

[35] D. E. Orr and K. J. L. Burg, "Design of a modular bioreactor to incorporate both perfusion flow and hydrostatic compression for tissue engineering applications," Annals of Biomedical Engineering, vol. 36, no. 7, pp. 1228-1241, 2008.

[36] U. G. Longo, A. Lamberti, N. Maffulli, and V. Denaro, “Tissue engineered biological augmentation for tendon healing: a systematic review," British Medical Bulletin, vol. 98, no. 1, pp. 31-59, 2011.

[37] F. Edom-Vovard and D. Duprez, "Signals regulating tendon formation during chick embryonic development," Developmental Dynamics, vol. 229, no. 3, pp. 449-457, 2004.

[38] J. L. Chen, Z. Yin, W. L. Shen et al., "Efficacy of hESC-MSCs in knitted silk-collagen scaffold for tendon tissue engineering and their roles," Biomaterials, vol. 31, no. 36, pp. 9438-9451, 2010.

[39] C. K. Kuo and R. S. Tuan, "Mechanoactive tenogenic differentiation of human mesenchymal stem cells," Tissue Engineering, Part A, vol. 14, no. 10, pp. 1615-1627, 2008.

[40] N. Juncosa-Melvin, J. T. Shearn, G. P. Boivin et al., "Effects of mechanical stimulation on the biomechanics and histology of stem cell-collagen sponge constructs for rabbit patellar tendon repair," Tissue Engineering, vol. 12, no. 8, pp. 2291-2300, 2006.

[41] J. H.-C. Wang, "Mechanobiology of tendon," Journal of Biomechanics, vol. 39, no. 9, pp. 1563-1582, 2006. 


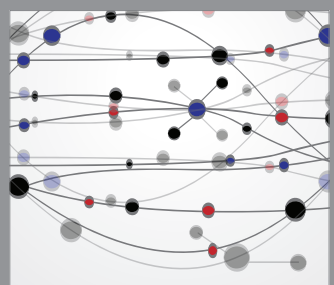

The Scientific World Journal
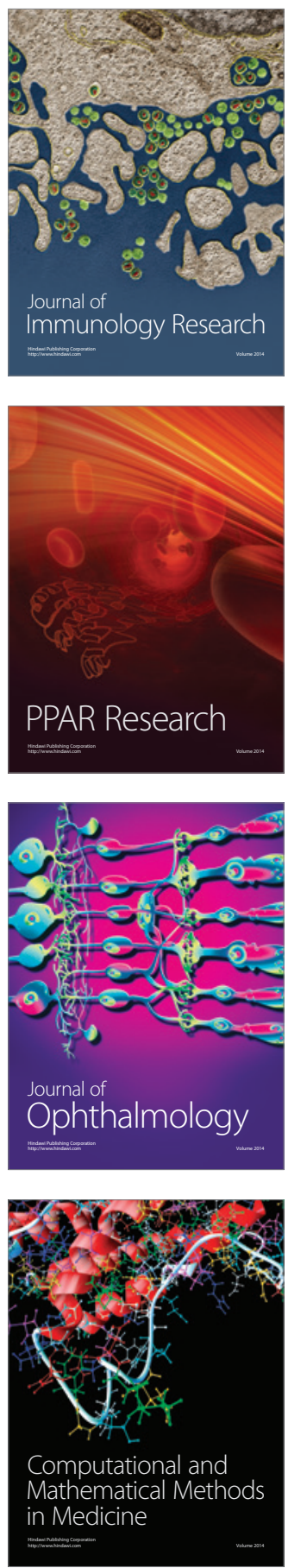

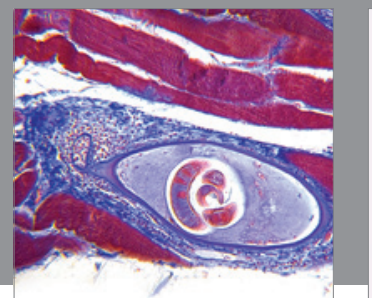

Gastroenterology

Research and Practice
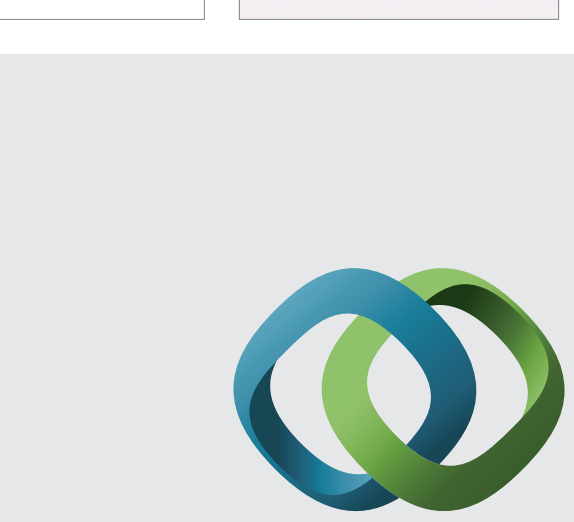

\section{Hindawi}

Submit your manuscripts at

http://www.hindawi.com
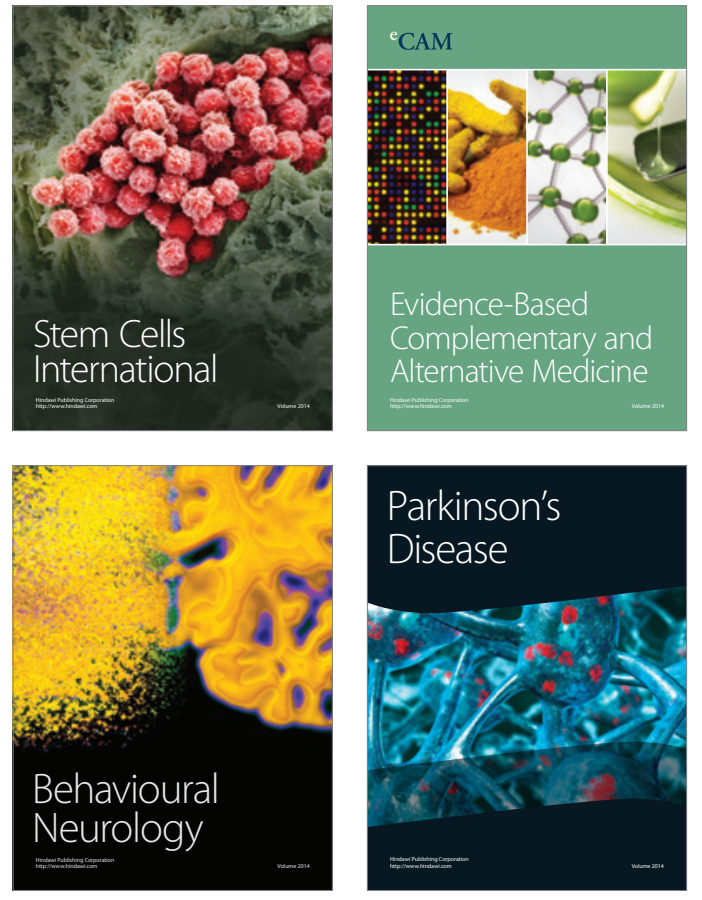
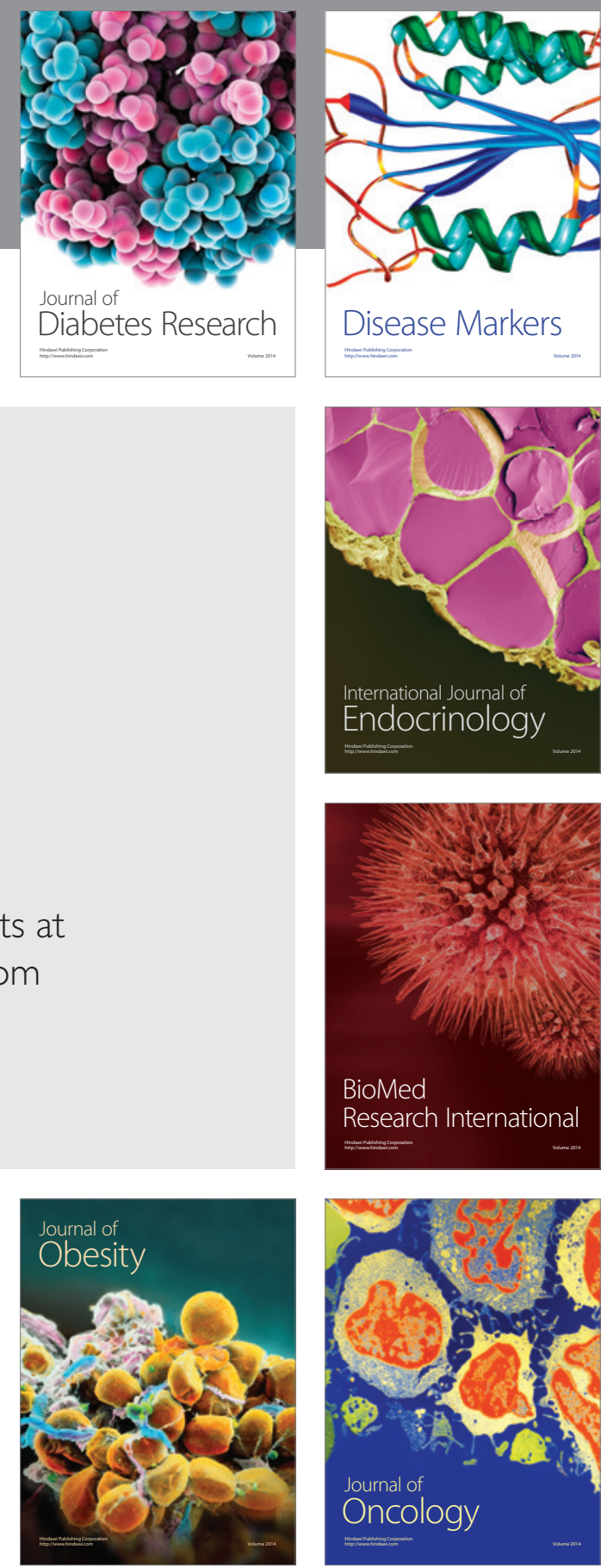

Disease Markers
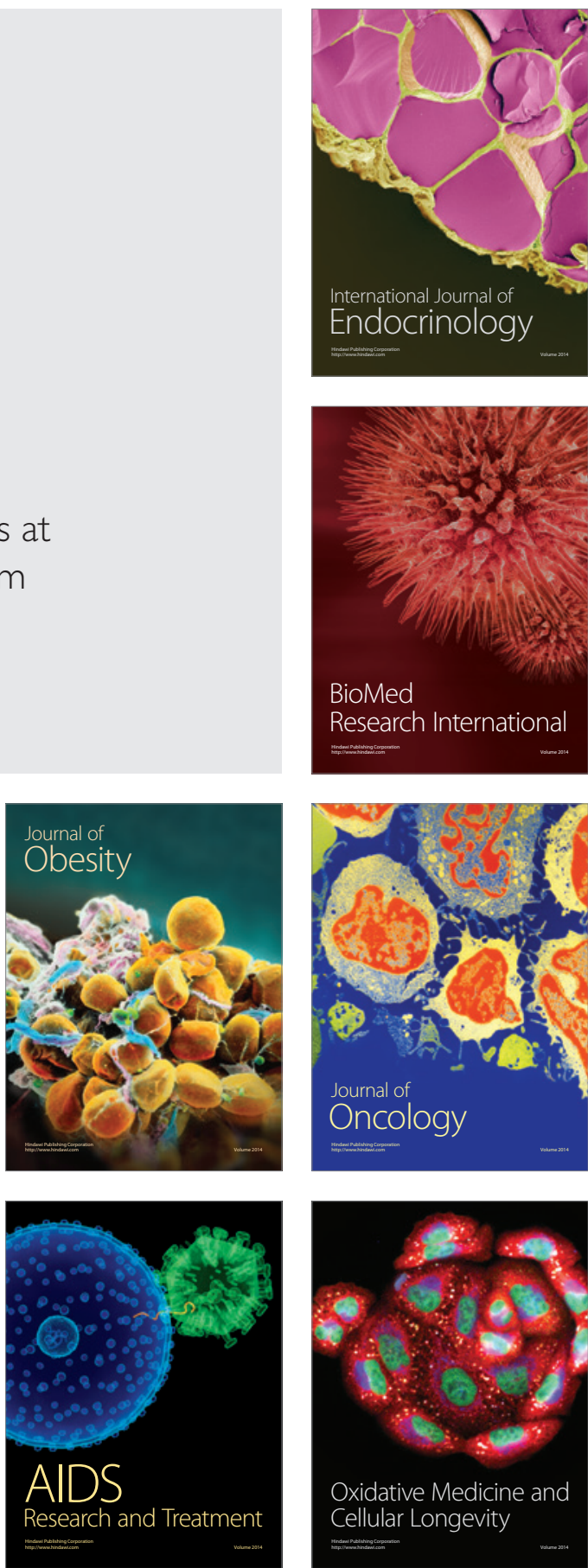